\title{
Major natural hazards in a tropical volcanic island: a review for Mayotte Island, Comoros archipelago, Indian Ocean
}

Jean-Christophe Audru ${ }^{1}$, Adnand Bitri ${ }^{2}$, Jean-François Desprats ${ }^{3}$, Pascal Dominique ${ }^{2}$, Guillaume Eucher ${ }^{4}$, Said Hachim ${ }^{5}$, Olivier Jossot ${ }^{6}$, Christian Mathon ${ }^{7}$, Jean-Louis Nédellec

${ }^{8}$, Philippe Sabourault ${ }^{9}$, Olivier Sedan ${ }^{2}$, Philippe Stollsteiner ${ }^{2}$, Monique Terrier-Sedan ${ }^{2}$,

1: BRGM Mayotte, BP 1398, 97600 Mamoudzou, Mayotte, France

Present address: BRGM Martinique, Lot. Miramar, Route Pointe des Nègres, 97200 Fortde-France, Martinique

2: BRGM, BP 36009, 45060 Orléans cedex 02, France

3: BRGM Languedoc-Roussillon, 1039 rue de Pinville, 34000 Montpellier, France

4: Société des mines de la Tontouta, BP T2, 98852 Nouméa, New-Caledonia

5: Conseil général de Mayotte, cellule risques majeurs, 97600 Mamoudzou, Mayotte

6: SAFEGE, 650 rue Becquerel, 34000 Montpellier, France

7: BRGM Provence Côte d'Azur, BP 168, 13276 Marseille cedex 09, France

8: BRGM Réunion, BP 906, 97478 Saint-Denis cedex, La Réunion

9: Ministère de l'Écologie, Direction générale de la prévention des risques, Grande Arche, 92055 Paris la Défense

\section{Corresponding author:}

Dr. Jean-Christophe AUDRU

BRGM Martinique, Lot. Miramar, Route Pointe des Nègres, 97200 Fort-de-France, Martinique

Email: jc.audru@brgm.fr

Tel: +(596) 596713005

Fax: +(596) 596712500 


\section{Abstract}

Mayotte is a French Overseas Territory of the Comoros archipelago. Since the 1980', Mayotte has developed quickly: its population has multiplied by four in less than 30 years, infrastructure expanded rapidly in lowlands and slums developed in steep areas (through deforestation) or close to riverbeds. This development urgently required steps to ensure the safety of urban areas.

From 2002 to 2006, a major programme of natural hazards evaluation and zonation was conducted by the French Geological Survey in the 17 districts of Mayotte. The programme resulted in the publication of the first single-hazard zonation maps for Mayotte, at 1:25 000scale in rural areas and at 1:10 000-scale in urban areas. Hazard maps regarding landslides and rock falls, stream floods, seismic lithological and topographical amplification potential, liquefaction potential and cyclonic marine submersion were produced for mayors and land planners. These atlases also included prevention guidelines to minimize risks associated with land-use or urbanization within hazard-prone areas.

This article presents the main achievements of the programme whose main problems were the absence of archives, of previous studies and the original volcanic geology of the island of Mayotte. The atlases highlight areas with numerous landslides, zones susceptible to flash floods, sectors likely to be submerged by storm surges and areas subject to seismic site effects due to thick volcanic weathered formations. This programme emphasizes the fundamental role in such tropical volcanic islands, of a good knowledge of the weathered formations, for the assessment of most natural hazards.

This initial hazard mapping represented the first step to achieve specific regulatory Risk Prevention Plans for an efficient land use risk mitigation and reduction policy in Mayotte.

Key-words: landslides, rock falls, floods, seismicity, storm surge, volcanic, alterites, Mayotte, Comoros 


\section{Introduction}

The "Natural hazards and erosion" programme was established from 2002 to 2006 between the BRGM (French Geological Survey) and the Mayotte General Council. The programme's goal was to describe natural hazards in Mayotte for land use planning. Since the 1980', Mayotte has developed quickly, its population has multiplied by four in less than 30 years (INSEE, 2007), infrastructure has expanded rapidly in lowlands, and many slums developed in steep areas (through deforestation) or along riverbeds. This development urgently required steps to ensure the safety of these urban areas.

Single hazard maps for landslides, stream floods, seismic lithological and topographical amplification potential, liquefaction potential, cyclonic marine submersion (in collaboration with Météo-France, the French meteorological service) and maps for potential soil erosion and runoff (in cooperation with CIRAD, the French agricultural research centre) were compiled for each district. Erosion and runoff processes and maps are not discussed here.

The maps are the product of a tight combination of several analyses: detailed field work and naturalistic expertise when the field was accessible (the main data source), inquiries among the population, stereoscopic analyses of 1:25 000 vertical aerial photos from 1997 and its derived orthophotograph (French National Geographical Institute), 50 m-grid digital elevation model from 1993 (French National Geographical Institute) and a derived slope model based on computing procedures proposed by Wilson and Gallant (2000). In some towns and villages, high resolution seismic and electric surveys were conducted to get seismic velocity profiles. When the field was inaccessible, maps were derived from low altitude aerial reconnaissance surveys.

The initial problem of the programme was to deal with the absence of any archive, except a few old newspapers. To compensate this, village elders were interviewed in Shimaore, the local dialect (Hachim, 2004), to see if there was evidence of hazardous phenomena in the local oral history or in old village parchments (written in Arabic). Historical information was also gathered from old sugar companies accounting journals (since 1845) which recorded 
cyclones that had devastated crops. This information was checked for its precision in time and space and about 85 were kept and plotted in a geographic information system layer (Fig. 1). These data were initially used as a field guide to check recent records. They were then compared, with great caution (considering uncertainties on the exact location, period, hazard, protection, destructions etc.) to hazard contours. They revealed some very old events (Hachim, 2004): earthquakes that had destroyed mosques in 1606 and 1679, trees planted at the upper limit of large floods in 1908, strong waves that had displaced ships hundred of metres inland in 1650 and 1690, conjunction of landslides and earthquakes in 1829 and 1993 etc. These data proved quite useful to accompany our simulations but needed to be used with caution.

On each field map, contours delineate the possible extent of one hazard, usually with three ranking levels of hazard occurrence: low, medium and high. Ranks were determined following the methodological guides to each hazard, based on the qualitative association of dimensions, severity, occurrence, and mitigation costs etc., recommended by the French Ministry for Environment. The main concepts of these guides are discussed later.

The contours were then digitized with the geographic information system Maplnfo, the common software used by all public services in Mayotte. GIS files included contours, values, classifications, field notes and description etc.

The programme results were compiled in six A3-format atlases for the 17 districts of Mayotte (Audru et al., 2004 to 2006a; Eucher et al., 2006). The atlases include a general description for each hazard in Mayotte, and some easy prevention tips and mitigation guidelines for affected areas. The second chapter is dedicated to the specific atlas districts. It comprises 1:25 000 single hazards maps and additional zooms at 1:10 000 scale in urban areas, in paper and GIS format: are also produced landslides and flood marks inventories (observable at the fieldwork dates), local geological map, local digital elevation model and its derived slope model, hydrological basic studies for the main streams (card format), and erosion runoff potential maps. The full bibliography and archive index of the programme is not 
detailed here as it is in each atlas. All the Mayotte atlases are open-file and freely available from the French Geological Survey website at www.brgm.fr.

These documents were the first hazard maps for Mayotte. They are intended to be easy-toread by non-specialist public, and to inform local authorities (municipalities, mayors, planners, developers, engineers, land owners etc.), and the public of the possible occurrence of hazardous natural phenomena in their territory. Presentation of some major results of the project is the main purpose of the present study.

\section{Geological and geomorphological characteristics of the study area}

Mayotte is a French Overseas Territory of the Comoros archipelago (Fig. 2a). Among thirty little islets, Mayotte includes two main islands called Grande-Terre ("Large Island") and Petite-Terre ("Little Island"); their total area is about $379 \mathrm{~km}^{2}$. Mayotte Island culminates on Grande-Terre at the Benara Peak at $660 \mathrm{~m}$. The population is over 186000 inhabitants (INSEE, 2007), one third living in the main city of Mamoudzou, the rest mostly in coastal villages (Fig. 2b).

Mayotte islands probably formed by two shield volcanoes (Stieltjes, 1988; Debeuf, 2004; Audru et al., 2006b) that were submarine from 15 to $10 \mathrm{My}$ and then sub-aerial post-10 My. Grande-Terre and Petite-Terre islands have a strong volcanic geomorphology with old craters and elongated hills formed by lavas flows (Fig. 2b). The two islands are surrounded by a large closed lagoon (1 $\left.100 \mathrm{~km}^{2}\right)$, one of the world biggest, that is almost completely surrounded by a barrier reef, cut by some channels. On land, the main formations that outcrop (Fig. 3) are Miocene-Pliocene basaltic and phonolitic lavas, pyroclastic projections and ash layers (Stieltjes, 1988). Large thicknesses of argillaceous weathered rocks overlie and intercalate the basaltic and phonolitic formations (Fig. 3). Volcanism continued on PetiteTerre until the Quaternary, with late trachytic ashes dated at approximately 7000 years BP (Zinke et al., 2003). The limestone coral reef began to build about $1.5 \mathrm{My}$ ago (Thomassin et al., 1989). The lagoon floor and the reef became emergent during the Last Glacial Maximum, 26000 years ago (Camoin et al., 2004), at which time meandering channels formed in the 
lagoon floor and karsts systems formed in the reef wall. These have been observed by submersible at $150 \mathrm{~m}$ depths (Dullo et al., 1998). The lagoon was reflooded 11600 years ago (Zinke et al., 2003).

Offshore, multibeam bathymetry acquired during the BathyMay survey (Audru et al., 2006b) revealed that Mayotte island stands $4400 \mathrm{~m}$ above the oceanic floor. Among hundreds of submarine volcanoes, deep canyons and huge debris-flows (up to $35 \mathrm{~km}$ of estimated runout), the bathymetry outlines large submarine plateaus that are probably bounded by active faults. These may represent the offshore extension of normal faults (Fig. 3) inferred on land and in the lagoon (Audru et al., 2006b).

Basaltic volcanoes and associated lavas flows give rise to an undulating topography of elongated hills (Fig. 2b), mantled with a blend of colluviums and alterites. Phonolitic domes form high steep pitons in this soft topography. The current geomorphological evolution is mainly characterized by erosion of the alterite mantle and the subsequent rapid silting up of the lagoon floor (Thomassin et al., 1989).

The programme did not manage to study the alterites in detail, but some observations were made to contribute to the hazard mapping. Weathered profiles partly correspond to existing descriptions (e.g. ISRM, 1981; Chilton and Fosters, 1995; Karpuz and Paamehmetoglu, 1997). Recent classifications (Wyns et al., 2004; Dewandel et al., 2006) are preferred for their simplicity and ease of use in the field. On top of the fresh bedrock, the alterites are divided into two units (Fig. 4): the lower isalterite (slight or no change in rock volume, preservation of the original rock structure) and the overlying alloterite (volume reduction related to mineralogical weathering processes, loss of the original rock structure). Alloterites of basalt form coloured soils, mostly light-grey to purple-red, that are rich in smectites (Stieltjes, 1988). Hydrothermal weathering of phonolitic domes generates white and red soils with high kaolinite content (Stieltjes, 1988). However, in some places, the bedrock-alterites boundary was correlated to S-wave velocity profiles acquired for seismology purposes. The increase of basalt weathering correlated directly with the S-wave velocity decrease, as is 
recently seen with P-waves velocity measurements in other environments (Gupta and Rao, 2001; Gokceoglu et al., 2009).

Because of this geological framework and of its geographical location, Mayotte is exposed to several natural hazards. The rainfall intensity (up to 1500 to $2000 \mathrm{~mm} / \mathrm{yr}$ ) and the tropical cyclones contribute to erosion, land instabilities, flooding and marine submersion, and offshore features such as faults may be responsible for the seismic activity recorded in Mayotte.

\section{Land instability hazard}

There are several qualitative or quantitative methods to produce landslide susceptibility maps (e.g. Pachauri and Pant, 1992; Gokceoglu and Aksoy, 1996; Soeters and Van Westen, 1996; Donati and Turini, 2002; Van Westen et al., 2003). However, initial data related to Mayotte landslides is limited to only one partial inventory at 1:50 000 (Thierry, 1996). Thus, our approach follows the French standard zonation method based on the dimensions, severity, human threat, prevention expenses etc., simplified to use the available Mayotte data. A heuristic approach was chosen, because it can provide qualitative landslide hazard maps for large areas in a relatively short time and with limited data (e.g. Leroi, 1996; Barredo et al., 2000). Prior to the field work, field guide maps were produced from an inventory of instabilities using typologies derived from Varnes (1978), analysis of vertical aerial photos from 1997, bedrock geology, slope maps, interviews and historical documents. The final hazard maps were based on extensive field mapping with experts' a priori knowledge of instability factors.

Land instabilities include mainly shallow rotational or translational landslides, superficial soil flows, scarps, creeping, hummocky surfaces, and rock falls and topples (Fig. 5). Paleolandslides were rarely observable when bedding was visible (in ashes for instance). Transport distance can be small (a few meters in rock falls) or large (up to $250 \mathrm{~m}$ from crown to toe along rotational structures). Landslides are observed frequently when compared with 
rock falls (247 km² vs. $67 \mathrm{~km}^{2}$ ), due to the abundance of argillaceous weathered basalts (the source of most landslides) vs. weathered phonolites (producing most rock falls).

On the resulting map (Fig. 6), the low hazard areas were characterized by extremely rare events of low intensity and severity, and slopes less than $8^{\circ}$ (slope value determined from field observations). In our methodology, a single landowner could afford protection expenses in a low hazard area. Small landslides, mainly due to regressive erosion, occur along steep clayey roadsides. Attempts to stabilize these small structures, mainly using worn-out tyre walls, are successful. Some erratic blocks are present in these areas but cannot move. The low hazard areas cover $62 \mathrm{~km}^{2}$, which means that only $16 \%$ of Mayotte territory is likely to be unaffected by land instabilities.

The medium level included old or small events (less than $5 \mathrm{~m}$ wide and less than $5 \mathrm{~m}$ deep), evidence of deformation in roads (i.e. undulations, cracks) or creeping in the topography; it also comprises poor hydrological conditions, extreme tips of propagation of blocks or landslides, downstream location of high hazard level sectors, and slopes from $8^{\circ}$ to $20^{\circ}$. Following other authors (e.g. Pachauri and Pant, 1992; Gokceoglu et al., 2005), and because of the lack of reliable data, slope values are considered as a landslide conditioning factor when producing landslide hazard map. In the methodology followed in this study, cooperation by a group of landowners is required to afford expensive stabilization measures. The medium hazard level mainly applies to low altitude elongated hills that represent ancient lava flows (inset Fig. 6). This rank affects $41 \%$ of Mayotte. Medium metric superficial landslides are observed mainly in urban areas along clayey hill flanks, in strongly weathered basalts, in colluvial slopes, in badlands and along gullies. Some medium landslides occur in PetiteTerre in cineritic and trachytic ashes due to their capacity for water infiltration, or in weathered basalts that overly ash layers. Rock falls of medium severity are produced by differential erosion. At the contact of lava flows over thick clayey palaeosols, underlying clays are quickly removed by erosion, which leads to the collapse of the overlying lava blocks.

The high level hazard areas comprise historic and active instabilities (more than $5 \mathrm{~m}$ wide and more than $5 \mathrm{~m}$ deep), probable areas of thick unstable alterites and/or unfavorable 
hydrological conditions (water retention, springs), deformed topography, probable occurrence sectors in the short- to medium-term, and slopes over $20^{\circ}$. The failure surfaces may form within the alterites (isalterite-alloterite boundary) or follow the bedrock-alterites contact. In such an area, there are no affordable stabilization measures. The high hazard level of land instability was mainly observed in high hills districts, i.e. elevation above $300 \mathrm{~m}$, which is in agreement with observations elsewhere (Pachauri and Pant, 1992; Ercanoglu and Gokceoglu, 2002), in slopes steeper than $20^{\circ}-30^{\circ}$ and in probably thick ( $>15 \mathrm{~m}$ ) alterites. For these high level areas, a security zone of $25 \mathrm{~m}$ (buffer zone) is added upstream and downstream to the initial hazard contour. The high level rank affects $43 \%$ of Mayotte territory (Fig. 6). These areas are a strong brake to land use, especially in urban areas, because the future mandatory Risk Prevention Plans based on these maps will prohibit any construction in such areas.

Large landslides (hectometric scale, several meters deep) are observed in badlands or in thick (over $100 \mathrm{~m}$ ) weathered phonolites (Fig. 7a); this is common in kaolinite-rich formations (Van Wyk de Vries et al., 2000). Del Potro and Hürlimann (2009) recently suggested that when kaolinite is dominant, which is the case of Mayotte weathered phonolites (Stieltjes, 1988), it significantly lowers the shear strength. This observation is also applicable to other weathered volcanics that may have a high cohesion and internal friction angle (up to $37^{\circ}$ ) but for which the increase of water content suddenly reduces the shear strength (Gostelow, 1991; Audru et al., 2006c; Yalcin, 2007).

The failure depths of the superficial and medium landslides seem to appear at the isalteritealloterite boundary while the sole of the large landslides seem to follow the alterites-bedrock boundary, but this has not been measured precisely. The residual topography derived from medium and large landslides is subjected to intense erosion and vegetation disappearance, which results in spectacular eroded badlands, locally called "padzas" (Fig. 7b). These are natural but may be dramatically accelerated by inappropriate land use (Audru et al., 2003). Planting specific trees (Acacia mangium) and herbs (Vetiver zizanioides) together with building small walls of gabions lowers the rain energy, reduces runoff and helps restoration 
of soil properties (Izard et al., 1999). Such forestry operations slow down or sometimes nearly stop the formation of badlands in Mayotte.

In this level area, blocks are massive (greater than $1 \mathrm{~m}^{3}$ and up to $50 \mathrm{~m}^{3}$ ); they are produced by erosion of phonolitic domes, and form a large mantle around the source. Formation of these blocks is the result of the initial phonolitic lava flow structure and the accompanying hydrothermal fracturing (Stieltjes, 1988). In basaltic lavas, vertical or horizontal fractures (related to lava cooling) produce large blocks $\left(>1 \mathrm{~m}^{3}\right)$ on the hill flanks. In the colluvial slopes, blocks derived from uppermost formations, or from in-situ weathering, may remain anchored in thick soils while others may fall over large distances and cause major damage and sometimes death when they strike houses. Dangerous rock falls were also observed along the coastline of Petite Terre, where low-cohesion strombolian cones (bombs, roped lava, slags, etc.) or cineritic and trachytic cliffs provide numerous blocks of about $10 \mathrm{~m}^{3}$. These falls are enhanced by strong marine erosion during high tides (over $4 \mathrm{~m}$ of amplitude around Mayotte) or cyclonic conditions. Sandstone-like pyroclastic formations of GrandeTerre are the only geological formation of Mayotte for which landslides or rock falls are nearly absent, unless they are altered (thin sliding surface) or reworked for urban purposes (small decompression features appear).

The ranking methodology may appear conservative, but this is the first analysis of its kind for Mayotte. This counterbalances initial uncertainties in superficial geology, mechanical properties of alterites, errors in the digital elevation model and derived slope models, field localization, etc. This methodology and its derived hazard contours proved suitable for Mayotte when landslides and rock falls struck homes and caused fatalities in medium and high level hazard areas, after heavy rains in 2003 and 2004.

Lithology, its derived alterites, and slope values are the most significant factors for land instabilities in Mayotte; this relationship is observed in other tropical environments (e.g. Nagarajan et al., 2000; Saldivar-Sali and Einstein, 2007; Deb and El Kadi, 2009). On such volcanic formations, triggering factor is heavy rainfall over a long period (Au, 1998; Deb and 
El Kadi, 2009), overpressure in perched aquifers, cyclonic winds (uprooting trees in already instable slopes) and improper agricultural (strongly erosive) practices.

\section{Flood hazard}

Mayotte has hundreds of intermittent gullies and about twenty streams that are nearly permanent (24 third-order streams in the Strahler classification). Watersheds are small, less than $25 \mathrm{~km}^{2}$. Field surveys for flood hazard zonation were conducted following the hydrogeomorphic French method, whose concept is that the floodplain outer limits contain the envelope curve of the past flood limits. These outer limits were determined by studying aerial photographs and through extensive fieldwork: identification of flood or high water marks, flood plain limits, bend envelopes, flooded area limits, aggradations zones, bank limits, jam sectors, bed loads, etc. The hazard level was based mainly on the evaluation of water depth and velocity during floods. There was no initial flood mapping or such archive in Mayotte, or historical flood marks. Anecdotes of floods were numerous but few were precise. The initial methodology was simplified to accommodate the available data, and was calibrated during heavy rains in 2003 and 2004 to improve its precision. This study was the first of its kind in Mayotte and the methodology was chosen for its reliability, ease of use and low cost compared to the hydrologic-hydraulic method. Three types of floods are described (Fig. 8) based on their origin, but they are poorly documented.

The floods due to urban runoff affect urban areas or villages (Fig. 8a). Typically, the infiltration is significantly reduced due to the construction of residences, buildings, sidewalks, car parks and roads, and to deforestation (Boyd et al., 1994; Gupta and Ahmad, 1999). Intense rains generate a very strong runoff whose consequences are amplified by the rapid saturation of the drainage system. There is also a strong drowning risk in ditches. The undersizing of most bridge spans and of older hydraulic systems, the lack of services that remove garbage and mud, and the effects of culverts, canals (which often prolongate natural channels) and ditches, lead to flooding. This is in agreement with other studies that describe how urbanization accelerates the increase in flood peak in tropical environments (e.g. Wong 
and Chen, 1994). In coastal villages, the flooding risk from surface water runoff is highest due to the combination of nearby steep topography, sometimes in a crater-like geometry, and impermeable surfaces. In these villages, the main highway, which runs all around the island, also forms a hydraulic dam due to under-fitted bridges.

Floods due to stagnant rainwater (Fig. 8b) affect flat and coastal lowlands that act as storage areas. They are characterized by low water level and very low water speed. These floods are related to insufficient capacity of soil infiltration and to under-fitted (old) drainage systems. These floods are frequent in Mamoudzou and in the coastal areas especially during high tides.

Flash floods affect gullies during the monsoon season from December to March. They result from the rapid concentration of water in small watersheds (Costa, 1987) into steep and usually dry gullies (Fig. 8c). These floods undermine banks, enlarge stream beds, produce scours, landslides and boulders accumulation, often erode agricultural soil (sociological consequences) and deposit large amounts of material under bridges. There is also a strong drowning risk especially when crossing fords and upon arrival of the flood wave. For the smaller watersheds, water levels rise and fall rapidly. In some gullies, the spill over under heavy rain conditions is mainly related to natural debris jams (plants, trees, collapsed embankments), to the winding of channels and the under-designed spans of old bridges. The elongated watersheds, the small surfaces and the steep slopes favour quick concentration, high water speeds and high potential for material transport (Schmittner and Giresse, 1996). Aggravating factors are runoff due to intense deforestation around urban areas, erosive agricultural practices and introduction or artificial jams (dumps) into the riverbeds.

The moderate level hazard area (Fig. 9) is introduced to take into account the large stagnation areas that commonly form after heavy rains in towns and villages. The water does not flow and is less than $50 \mathrm{~cm}$ deep, but can disturb the economic activity for a long time (Fig. 10a). 
The medium hazard zones usually occupy sectors where water speeds are estimated less than $0.5 \mathrm{~m} / \mathrm{s}$ and where water depths are less than $1 \mathrm{~m}$. These are found in the floodplains, between meanders and usually at river mouths and downstream lowlands.

The high level of flood hazard is characterized by high water speeds estimated over $0.5 \mathrm{~m} / \mathrm{s}$, and annual floods over $1 \mathrm{~m}$ deep. Observations of floods during the project helped guide the interpretation (Fig. 10b). Along gullies, the high level contours follow more or less the main envelope surface of the riverbed. The contour limits are increased by $10 \mathrm{~m}$ to take into account map errors, to anticipate riverbank erosion, and to prevent construction very close to the gully. The high flood hazard affects $12 \%\left(44 \mathrm{~km}^{2}\right)$ of Mayotte territory mainly along the riverbeds and their meander envelopes (Fig. 9). The medium level affects about 1\% within the bends envelope and at the river mouths. The moderate level affects $5 \%$ of the territory, mainly in flat urban areas.

Peak discharge estimations of centennial and decennial events were also evaluated for the main watersheds despite the lack of gauging stations and of reliable automatic weather stations in the country. Mayotte watersheds have steep slopes, they were poorly gauged and rainfall data were very limited (around 5 years on 2 stations at the time of the project). Due to the tropical environment (e.g. Chow, 1959; Hall 1984; Alcoverro et al., 1996; Ramachandra et al., 1999), the rational method (initially Mulvaney, 1851) was applied to evaluate decennial flows and was complemented with the gradex method (Guillot, 1993) for centennial events. Its accuracy for decennial and centennial events appeared acceptable for quick practical use in Mayotte. The rational method runoff coefficient is a function of the soil type and drainage basin slope, and is adapted to Mayotte based on statistical data derived from the two stations with several years of observation. The results for each stream are displayed in a card format which outlines the main danger related to the stream (Fig. 10c).

The Ouroveni River has the largest watershed (drainage basin) in Mayotte with an area of 24 $\mathrm{km}^{2}$. The total channel length is about $124 \mathrm{~km}$ and the main riverbed is $14 \mathrm{~km}$ long. Peak discharges on the Ouroveni were estimated using a rainfall rate of $190 \mathrm{~mm} /$ day and a runoff coefficient of 0.4 for decennial frequencies. Application of the gradex method gave a runoff 
coefficient of 0.62 for a rainfall of $285 \mathrm{~mm} /$ day for the centennial frequency. The concentration time was estimated from the average concentration time derived from the classical Kirpich/Giandotti/Passini evaluations. A decennial peak flow of $193 \mathrm{~m}^{3} / \mathrm{s}$ and a centennial flow of $435 \mathrm{~m}^{3} / \mathrm{s}$ at the downstream river end were derived from these estimates. These values are not huge, but at Mayotte scale and compared to the coastal village configurations, they are high enough to suddenly deposit significant amounts of eroded material downstream, mainly silts and clays and to cause dangerous and unpredictable riverbanks destabilization.

\section{Seismic hazard}

The French SisFrance catalogue of historical earthquakes (www.sisfrance.net) includes three historical events in 1936 (intensity VI), in 1941 and in 1952 around Mayotte. Seismic activity recorded in Mayotte by the USGS National Earthquake Information Centre web site (http://earthquake.usgs.gov) includes three shallow earthquakes (April 1993 M:5; December 1993 M:5.2; September 2001 M:4.1) with epicentres located within 70 km of Mayotte. Local administrative notes suggested that the 1993 earthquake had generated 1.7 million euros of damages in Mayotte, mostly (90\%) on individual houses.

Given these observations, regional seismic hazard evaluations attributed an epicentral intensity of VII to VIII to the 1993 event and calculated a peak ground acceleration (PGA) value of $0.15 \mathrm{~g}$ at the bedrock for current buildings (Terrier et al., 2000; Bour and Sedan, 2002). It was thus decided to study more precisely the local seismological context to establish safety limits for public buildings construction. During the programme, several seismic surveys were conducted throughout the island to determine soils characteristics. The spectral analysis of surface waves method (SASW; Stokoe and Nazarian, 1983) provided shear wave velocities in the subsurface formations (Fig. 11a), and the horizontal-to-vertical spectral ratio method (HVSR; Nakamura, 1989) helped to quickly estimate the site resonance frequencies at specific locations (Fig. 11b). 
Numerical simulations derived from the CyberQuake software (BRGM, 1998) used the results of the geophysical studies, of the geological fieldwork and of borehole logs to produce soil responses to seismic accelerations. Elastic response spectra and PGA values were produced for representative soil columns, which were much more precise for construction engineers than those derived from the regional seismic hazard assessment (Fig. 11c).

As demonstrated by the previous seismic microzonation of downtown Mamoudzou (Sabourault et al., 2002), numerical simulations outlined local amplifications of seismic movements due to strong site effects (Fig. 11c). Such data showed that thick alterites, or a series of alternating massive basalts with strongly weathered basalts (see Fig. 4) could generate strong impedance contrasts and increase the PGA by 2 or 3 times. Simulations (adapted to public buildings exigencies) of maximum horizontal ground acceleration gave values of $0.26 \mathrm{~g}$ in thick trachytic ashes, 0.30 to $0.35 \mathrm{~g}$ in depression fills (estuarine, marine or terrestrial sedimentary formations) with low $\mathrm{S}$ waves velocities (120 to $140 \mathrm{~m} / \mathrm{s}$ ), $0.38 \mathrm{~g}$ in thick basalt alterites (S waves velocities from 250 to $420 \mathrm{~m} / \mathrm{s}$ ) and $0.39 \mathrm{~g}$ were found for thick trachytic ashes (S waves velocities from 275 to $450 \mathrm{~m} / \mathrm{s}$ ) lying on top of limestone reef formations. The bedrock S wave velocities ranged from 500 to $800 \mathrm{~m} / \mathrm{s}$.

The liquefaction potential was first estimated through qualitative properties (lithology, groundwater level, etc.) to produce susceptibility maps. Large mangroves, estuarine horizons and sandy coasts, as well as reclaimed land associated with a superficial water table were considered to be prone to liquefaction (Fig. 12). In a few sites dedicated to future civil engineering projects, soil liquefaction susceptibility was been estimated more precisely, based on the French seismic building codes PS92 (AFNOR, 1995, Monge et al., 1998) and using (Faccioli and Resendiz, 1976) geology, hydrology, Atterberg limits, granulometry etc. (Fig. 11d). A quantitative evaluation was made, based on the cyclic stress ratio concept (after Seed et al., 1983) and on the overall liquefaction intensity defined by Iwasaki et al. (1984). In the studied sites, most samples of soil (alterites) outlined a spread granulometry with an elevated content of clays and fines. These formations had an Iwasaki index smaller than 5, which indicated a low probability of liquefaction. Ashes had a homogeneous granulometry 
with a high content of big particles, and an Iwasaki index of 0 (no liquefaction). Samples from silty sand sites displayed granulometries that could favour liquefaction but they had an Iwasaki index of 0.6 to 4.1 which indicated liquefaction was not likely. This results show the uncertainty of liquefaction evaluation in suspected areas and why the construction of public buildings in Mayotte is now not recommended without a specific seismic study.

Topographical amplification was estimated based on the AFNOR recommendations (1995) depending mainly on the topographical highs geometry and a layer of possible topographical amplification was added (Fig. 12). The resulting seismic map highlighted lithological site effects, liquefaction susceptibility and topographical amplification. It was a very qualitative map but it was intended to encourage planners and engineers to include a seismic study before any public or major construction.

There was no field evidence of on land active faults even through recent structures had been inferred offshore in the lagoon (Audru et al., 2006b). Surface faulting and related seismogenic activity were excluded from the programme.

Based on interviews and historical documents, but without strong field evidence, it was suspected that local earthquakes would trigger some landslides. Historical documents (Gevrey, 1870) reported some mass movements triggered by the 1829 event (imprecise locations). An old newspapers reports that the $1993(\mathrm{Mb}=5.2)$ earthquake triggered several superficial landslides in Mayotte. Field work to locate these landslides identified hill slopes not steeper than $25^{\circ}$ in basaltic alterites. The earthquake occurred during the monsoon season and the alterites where probably water-saturated, which helped destabilisation on relatively low-angle slopes. Such features are commonly observed in tropical weathered formations experiencing earthquakes (e.g. Garwood et al., 1979; Bommer et al., 2002; Capra et al., 2003) and have been modelled since (Peng et al., 2009, Miles and Keefer, 2009).

\section{Cyclonic surge}

The programme focused on the submersion effects along the coastline during cyclones, to estimate the maximum water-level elevation expected during such phenomena. The storm 
surge is the offshore rise of seawater associated with the low pressure due to a tropical cyclone.

A numerical predictive model, based on depth-integrated equations of motion and continuity and on existing models, was undertaken by Météo-France for the project (Daniel, 1996). Changes in maximum surge elevations are forced by time-varying wind-stress and pressure gradient forces, which depend on the cyclone's location, minimum pressure, and size, measured from the eyewall out to the location of maximum wind velocity.

The similarity between observed and modelled storm surges has been validated for 15 years of observation in the French West Indies and in the Pacific French islands (Daniel, 1996). To provide atlases of pre-computed surges, the model needed a tropical cyclone climatology that gave a broad view of cyclones likely to hit the area. The simulation was based on three standard ("regular") cyclones that hit Mayotte in the past 20 years (Perraudin and Bénito, 2002): "Kamisy" in 1984 (winds at 62 kt, 982 hPa at Mayotte, many ships transported aground, 25 million euros damage), "Feliksa" in 1985 (winds at 63 kt, $246 \mathrm{~mm}$ of rain, 978 hPa at Mayotte, 9 million euros damage) and "Astride" in 2000 (winds at $45 \mathrm{kt}, 995 \mathrm{hPa}$ at Mayotte). Partial meteorological data was available (wind, temperature, pressure) but there was no value for the sea surface height. Simulations were also based on an extreme cyclone ("Hary") that had strongly hit the neighbouring Réunion Island in 2002. For calculations and simulation purposes, this extreme cyclone was translated geometrically just above Mayotte Island (Météo-France, 2004).

Among standard cyclones, "Feliksa" generates a maximum storm surge of $1.14 \mathrm{~m}$ within the lagoon (Fig. 13a) which corresponds to a maximum inundation height of $4.2 \mathrm{~m}$ along the coastline. The storm surge is up to $3.84 \mathrm{~m}$ for the pseudo-cyclone "Hary" (Fig. 13b) which corresponds to a maximum submersion height of $6.9 \mathrm{~m}$ along the coastline. The resulting surge maps (Fig. 14) predict the highest surge levels along the coastline, based on the known cyclones.

The high level of cyclonic submersion hazard corresponds to the high probability of occurrence of a standard cyclone. It is determined (Fig. 14) in front of each calculation node 
by an indicative upper limit inland (normalised to the "zero" altitude on land) which corresponds to the arithmetic sum of i) the highest tides altitude $(4.2 \mathrm{~m})$, ii) the local value of the standard cyclone surge and iii) an empiric value of swell height. The effective swell height is assumed to be $0.6 \mathrm{~m}$ behind mangrove coastlines, or $0.9 \mathrm{~m}$ behind sandy coastlines based on the observations of cyclonic wave dissipations in mangroves (Mazda et al., 1997; Massel et al., 1999).

The medium hazard zone corresponds to the low probability of occurrence of an extreme cyclone and is determined by the same process, using exceptional cyclonic surge values.

The estimated contours of inland storm surge inundation (Fig. 14) show that all coastal villages are deeply affected inland in case of such cyclones. For some villages, calculated values are supported by oral history or interviews of elders who had experienced cyclone inundations in the past century, especially around Mamoudzou and in the south of GrandeTerre. The accuracy of this simple estimation of the storm surge and associated inundation is limited by the lack of basic data, but it still helps mayors to plan construction outside the estimated submersion zone. A more accurate estimation would include estimating the cyclonic waves within the lagoon, which can increase or decrease the wave amplitude (Gourlay, 1996).

\section{Discussion}

The major natural hazards are a significant concern to the development of villages and towns in Mayotte. The high and medium levels of land instabilities affect $84 \%$ of Mayotte territory and $45 \%$ of the urbanized surface of Mayotte (in 2007). The high and medium levels of floods affect $12 \%$ of the urbanized surface of Mayotte; the standard cyclone submersion zone affects $14 \%$ of the coastal villages' surface, and the extreme cyclone submersion zone up to $23 \%$.

The atlases are the first of their kind in Mayotte and despite a conservative ranking due to the lack of initial data, they provide an initial tool for safe land planning. Their accuracy can be improved by regular inclusion of new data and the application of new methodologies. For 
instance, maps of the alterites/bedrock boundaries are very useful and innovative (Audru et al., 2003). Detailed mapping of these formations, their weathering index (see Fig. 4), their estimated thickness and some easy-to-get geophysical characteristics (penetration index) would provide a useful tool for much more precise landslide hazard mapping, especially in areas of future urbanization. Another improvement to the mapping of landslide potential would be the extraction of fuzzy if-then rules combined with field rules. When this technique was applied in Turkey, landslides were found to be located in the very high- and highsusceptibility zones of the landslide susceptibility map (Ercanoglu and Gokceoglu, 2002; Miles and Keefer, 2009). Recent work also takes into account the seismic topographic effects and run-out behaviour analysis (Peng et al., 2009) to provide a simulation of a complete set of landslide zones, including source, sliding and deposition areas. A methodology that associates seismology and landslides evaluation would be well adapted to Mayotte, especially in inaccessible areas.

Mapping alterites may also produce a better understanding of flooding. Recent work carried out in French Polynesia (Bouvier and Denat, 2006) has demonstrated the contributions of weathered or non-weathered geological formations to the development of rain-flow models. Another recent concept (Maréchal et al., 2003; Wyns et al., 2004) outlines the water capacity of alterites and the relationship between the alterites-bedrock boundary, the water table position and the aquifer drainage towards the rivers. These new concepts may be valuable for the floods study and for a better peak discharge evaluation of Mayotte.

Mapping alterites will also help to adapt seismic acceleration and lithological site effects on various lithological cross-sections. Combined with SASW surveys, these data help to classify the soils within the new Eurocode 8 soil classification (new European seismic codes). Integration of these with PGA for representative lithological columns could be a powerful tool for engineering design, and could be applicable to tropical volcanic islands in seismically active zones, e. g. the Caribbean region.

The tsunami hazard has not yet been studied in Mayotte. Far sources are not a significant concern. In December 2004, the Sumatra tsunami induced only a small tidal surge in 
Mayotte (Obura, 2006), due to its location in the shadow of Madagascar Island. Observations on similar islands (surrounding lagoon and a steep barrier reef) may apply to Mayotte. In Polynesia, Schindelé et al. (2002) show that the nearly vertical barrier reef forms an effective buttress against the tsunami waves. However, swells rush into the lagoon through the channels that cut the reef. Simulations need to be developed to identify exposed areas along the coastline.

Closer to Mayotte, within 500 km, active offshore faults of the East African Rift system (Malod et al., 1991) generate normal focal mechanism earthquakes that rarely exceed magnitude 6 and are unlikely to generate tsunamis. However within Mayotte, coastal landslides or huge submarine landslides and cliffs may represent a direct tsunami threat (Audru et al., 2004 to 2006b) as evidenced in other shores experiencing landslides (e. g. Tapin et al., 2001; Hasiotis et al., 2002). The waves generated by single coastal landslides can be violent and devastating (Schindelé et al., 2002) and their proximity induces extremely short propagation delays. Recent simulations on two-dimensional models based on the depth-averaged flow equations provide useful information even in such complex cases (Serrano-Pacheco et al., 2009) and may support the installation of early warning systems in coastal villages. Further work on seismic hazard should also emphasize analysis of the kilometric faults observed within the lagoon and across the submarine island slope (Audru et al., 2006b), that could be responsible for the moderate seismicity recorded in Mayotte.

\section{Conclusions}

The "Natural hazards and erosion" programme, led from 2001 to 2006 in Mayotte by the French geological survey, was the first step to acquire knowledge that will guide planning and safe development of Mayotte in hazard-prone areas.

The lack of any previous study or archive was the main initial problem of the project. National methodologies were simplified to fit the available data and the geological context of Mayotte. The resulting hazard maps may appear conservative due to these aspects. More accurate evaluation of land instabilities, of peak discharges and of seismic site effects is now heavily 
dependent on geological mapping of alterites. Moreover, detailed multibeam bathymetry within the lagoon will improve swell and cyclonic surges evaluation, and help to develop coastal facilities in accord with the sustainable tourism development goal. Further assessment of seismic and tsunami hazard in Mayotte also requires a better knowledge of the local features.

This little island provides a complete natural laboratory for these evaluations. An accurate knowledge of natural hazards in such a small and populated island has obvious implications for emergency response, public administration, land management and in the long-term, for the social development of the island. Risk Prevention Plans may help to constrain the development of human activities in exposed areas and to reduce the exposure of people and activities already installed in hazardous areas.

\section{Acknowledgments}

The authors wish to thank the French Ministry for Industry, the Mayotte General Council and the Public Service Department of the French Geological Survey for supporting and funding the "Natural hazards and erosion » programme. The programme also benefited from the active participation of Ms. Guilbert and Imbault and of Mr. Auber, Frissant, Maurillon, Moiriat, Rançon, Roubichou and Zornette of the French Geological Survey.

The authors are also grateful to Prof. Dr. Gokceoglu, to Dr. Guillou-Frottier and to an anonymous reviewer for their helpful and constructive comments to our initial manuscript. We thank Ms. Cahill of IRBA Co., NZ, for kindly reviewing our English text.

\section{Bibliography}

AFNOR, Agence Française de Normalisation, 1995. Paraseismic building codes: PS92 building rules. AFNOR, Paris, norme française NF P06-013 (in French).

Alcoverro, J., Corominas, J., Gomez, M., 1999. The Barranco de Ara's flood of 7 August 1996 (Biescas, Central Pyrenees, Spain). Engineering Geology 51, 237-255. 
Au, S.W.C., 1998. Rain-induced slope instability in Hong Kong. Engineering Geology 51, 136.

Audru, J.C., Mathon, C., Desprats, J.-F, Sabourault, P., Guillobez S., 2003. Superficial formations and natural hazards in Mayotte Island. Géologues 137 (in French).

Audru, J.C., Bitri, A., Desprats, J.-F., Mathon, C., Maurillon, N., Nédellec, J.-L., Jossot, O., Rançon, J.-P., Sabourault, P., Sedan, O., Terrier-Sedan, M., Zornette N., with collaboration of Stollsteiner, P. (Antéa), Guillobez, S. (Cirad), Daniel, P., Haie B. (Météo-France), 2004. Natural hazard atlases for Mayotte Island, districts of Mamoudzou, Koungou, Dzaoudzi and Pamandzi. Open-file BRGM report RP-53037-FR (in French).

Audru, J.C., Desprats, J.-F., Eucher, G., Jossot, O., Mathon, C., Nédellec, J.-L., Rançon, J.P., Sedan, O., Zornette, N., with collaboration of Stollsteiner, P. (Antéa), Guillobez, S. (Cirad), Daniel, P., Haie B. (Météo-France), 2004. Natural hazard atlases for Mayotte Island, districts of Chiconi, Ouangani, Sada and Chirongui. Open-file BRGM report RP-52662-FR (in French).

Audru, J.C., Auber, B., Desprats, J.-F., Frissant, N., Jossot, O., Mathon, C., Moiriat, D., Nédellec, J.-L., Sedan, O., Zornette N., with collaboration of Guillobez, S. (Cirad), Daniel, P., Haie B. (Météo-France), 2004. Natural hazard atlases for Mayotte Island, districts of Bandraboua and Tsingoni. Open-file BRGM report RP-53116-FR (in French).

Audru, J.C., Auber, B., Desprats, J.-F., Eucher, G., Jossot, O., Mathon, C., Moiriat, D., Nédellec, J.-L., Sedan, O., Zornette N., with collaboration of Guillobez, S. (Cirad), Daniel, P., Haie B. (Météo-France), 2005. Natural hazard atlases for Mayotte Island, districts of Mtsamboro, Acoua and Mtsangamouji. Open-file BRGM report RP-53194-FR (in French). 
Audru, J.C., Eucher, G., Desprats, J.-F., Jossot, O., Mathon, C., Nédellec, J.-L., Sedan, O., Zornette N., with collaboration of Guillobez, S. (Cirad), Daniel, P., Haie B. (Météo-France), 2006a. Natural hazard atlases for Mayotte Island, districts of Bandrélé and Dembéni. Openfile BRGM report RP-53678-FR (in French).

Audru, J.C, Guennoc, P., Thinon, I., Abellard, O., 2006b. BATHYMAY: underwater structure of Mayotte Island revealed by multibeam bathymetry. Comptes-Rendus Geosciences 338 (16), 1240-1249.

Audru, J.C., Nédellec, J.L., Mathon, C., Mompelat, J.M., 2006c. Geomechanical characterization of surface formations and instabilities in French Polynesia. Symposium on French Research in the Pacific, Tahiti, 9-12 October 2006.

Barredo, J.I., Benavides, A., Hervhas, J. van Westen, C.J., 2000. Comparing heuristic landslide hazard assessment techniques using GIS in the Tirajana basin, Gran Canaria Island, Spain. International Journal of Applied Earth Observation and Geoinformation 2 (1), $9-23$.

Bommer, J. J., Benito, M. B., Ciudad-Real, M., Lemoine, A., López-Menjívar, M. A., Madariaga R., 2002. The El Salvador earthquakes of January and February 2001: context, characteristics and implications for seismic risk. Soil Dynamics and Earthquake Engineering $22(5), 389-418$.

Bour, M., Sedan, O., 2002. French paraseismic regulations; Mayotte's case study. BRGM report no RP-51841-FR (in French) 
Bouvier, C., Denat, L., 2006. Estimation of rare floods on Tahiti and Raiatea watersheds. Development and implementation of a distributed rainfall-runoff model. IRD Montpellier report, Convention POL/06/011 (in French).

Boyd, M.J., Bufill, M.C., Knee R.M., 1994. Predicting pervious and impervious storm runoff from urban basins. Hydrological Science Journal 39, 321-332.

BRGM, French Geological Survey, 1998. CyberQuake: a computer aided design tool for evaluating seismic soil response, http://software.brgm.fr.

Camoin G., Montaggioni L., Braithwaite, C., 2004. Late glacial to post glacial sea levels in the Western Indian Ocean. Marine Geology 206, 119-146.

Capra, L., Lugo-Hubp, J., Borselli, L., 2003. Mass movements in tropical volcanic terrains: the case of Teziutlán (México). Engineering Geology 69 (3-4), 359-379.

Chilton, P.J., Foster, S.S.D., 1995. Hydrogeological characterization and water-supply potential of basement aquifers in tropical Africa. Hydrogeology Journal 3 (1), 36-49.

Chow, V.T., 1959. Open Channel Hydraulics. McGraw-Hill, New York.

Costa, J.E., 1987. Hydraulics and basin morphometry of the largest flash floods in the conterminous United States. Journal of Hydrology 93 (3-4), 313-338.

Daniel, P., 1996. A real-time system for forecasting hurricane storm surges over the French Antilles. In Small Islands (American Geophysical Union Ed.): marine science and sustainable development, coastal and estuarine studies 51, 146-156. 
Deb, S.K., El Kadi, A.I., 2009. Susceptibility assessment of shallow landslides on Oahu, Hawaii, under extreme-rainfall events. Geomorphology 108 (3-4), 219-233.

Debeuf D., 2004. Structural and volcano-magmatic evolution of Mayotte, Comoros archipelago, Indian Ocean. Unpublished PhD thesis, 2004, La Réunion University (in French).

Del Potro, R., Hürlimann, M., 2009. The decrease in the shear strength of volcanic materials with argillic hydrothermal alteration, insights from the summit region of Teide stratovolcano, Tenerife. Engineering Geology 104, 135-143.

Dewandel, B., Lachassagne, P., Wyns, R., Maréchal, J.C., Krishnamurthy, N.S., 2006. A generalized 3-D geological and hydrogeological conceptual model of granite aquifers controlled by single or multiphase weathering, Journal of Hydrology, 330 (1-2), 260-284.

Donati, L., Turrini, M.C., 2002. An objective method to rank the importance of the factors redisposing to landslides with the GIS methodology: application to an area of the Apennines (Valnerina; Perugia, Italy). Engineering Geology 63, 277- 289.

Dullo, W.C., Camoin, G.F., Blomeier, D., Colonna, M., Eisenhauer, A., Faure, G., Casanova, J., Thomassin, B.A., 1998. Morphology and sediments of the fore-slopes of Mayotte, Comoros Islands: direct observations from a submersible. Specialized Publication of the International Association of Sedimentologists 25, 219-236.

Ercanoglu, M., Gokceoglu, C., 2002. Assessment of landslide susceptibility for a landslideprone area (north of Yenice, NW Turkey) by fuzzy approach. Environmental Geology 41 (6), 720-730. 
Eucher, G., Audru, J.C., Bouleau, E., Desprats, J.-F., Djaco, E., Jossot, O., Nédellec, J.-L., Vigneau A., with collaboration of Guillobez, S. (Cirad), Daniel, P., Haie, B. (Météo-France), 2006. Natural hazard atlases for Mayotte Island. Districts of Boueni and Kani Keli. Open-file BRGM Report no. RP-55077-FR (in French).

Faccioli, E., Resendiz, D., 1976. Soil dynamics behaviour including liquefaction. In C. Lomnitz (Ed.), Seismic risk and engineering decision, Elsevier, Amsterdam, The Netherlands, 98-109.

Garwood, N.C., Janos, D.P., Brokaw, N., 1979. Earthquake-caused landslides: a major disturbance to tropical forests. Science 205, 997-999.

Gevrey, A., 1870. Essay on Comoros, Éditions du Baobab, 1997 (in French).

Gokceoglu, C., Aksoy, H. 1996. Landslide susceptibility mapping of the slopes in the residual soils of the Mengen region (Turkey) by deterministic stability analyses and image processing techniques. Engineering Geology 44 (1-4), 147-161.

Gokceoglu C., Sonmez, H., Nefeslioglu H.A., Duman, T.Y., Can, T., 2005. The 17 March 2005 Kuzulu landslide (Sivas, Turkey) and landslide-susceptibility map of its near vicinity. Engineering Geology 81, 65-83

Gokceoglu, C., Zorlu, K., Ceryan, S., Nefeslioglu, H.A., 2009. A comparative study on indirect determination of degree of weathering of granites from some physical and strength parameters by two soft computing techniques. Materials Characterization 60, 1317-1327. 
Gostelow, P., 1991. Rainfall and landslides. In: Almeida-Teixeira, M.E., Fantechi, R., GomesCoelho, A. (Eds.), Prevention and Control of Landslides and Other Mass Movements. Commission of European Communities, Brussels, 139-161.

Gourlay, M.R., 1996. Wave set-up on coral reefs. 1. Set-up and wave generated flow on an idealized two dimensional horizontal reef. Coastal Engineering 27, 161-193.

Guillot, P., 1993. The arguments of the gradex method: a logical support to assess extreme floods. International Association of Hydrological Sciences Publication 213, 287-298.

Gupta, A.S., Ahmad R., 1999. Geomorphology and the urban tropics: building an interface between research and usage. Geomorphology 31 (1-4), 133-149.

Gupta, A.S., Rao, K.S., 2001. Weathering indices and their applicability for crystalline rocks, Bulletin of Engineering Geology and the Environment 60, 201-221.

Hachim, S., 2004. Disasters! Mayotte loses her memory. Unpublished MSc(Hons) in Geography, Montpellier University (in French).

Hall, A.J., 1984. Hydrology in tropical Australia and Papua New Guinea. Hydrolological Sciences Journal 29 (4), 399423.

Hasiotis, T., Papatheodorou, G., Bouckovalas, G., Corbau, C., Ferentinos, G., 2002. Earthquake-induced coastal sediment instabilities in the western Gulf of Corinth, Greece. Marine Geology 186, 319-335.

ISRM, International Soil And Rock Mechanics, 1981. Rock characterization, testing and monitoring, ISRM suggested methods. Brown, E.T., (Editor), Pergamon Press, Oxford. 
INSEE, Institut National de la Statistique et des Études Économiques, 2007. Population Information Newsletter 39 (in French).

Iwasaki, T., Arakawa, T., Tokida, K.-I., 1984. Simplified procedures for assessing soil liquefaction during earthquakes. Soil Dynamics \& Earthquake Engineering 3 (1), 49-58.

Izard, J.M., Soumille, O., Seng, P., Vallée G., 1999. Agromanagement of soils and cropping systems. International workshop on agromanagement of soils and cropping systems, Rasolo and Raunet (Eds), CIRAD, Antsirabe, Madagascar, 509-518 (in French).

Karpuz, C., Pasamehmetoglu, A.G., 1997. Field characterisation of weathered Ankara andesites. Engineering Geology 46 (1), 1-17.

Leroi, E., 1996. Landslide hazard-risk maps at different scales: objectives, tools and developments. In: Landslides, Proceedings of the International Symposium on Landslides, Trondheim, Senneset Editor, 35-52.

Malod, J.A., Mougenot, D., Raillard, S., Maillard, A., 1991. New Constraints on the kinematics of Madagascar; structures of the Davie ridge, Comptes-Rendus de l'Académie des Sciences 312, 1639-1646 (in French).

Maréchal, J.C., Wyns, R., Lachassagne, P., Subrahmanyamd, K., Toucharda, F., 2003. Vertical anisotropy of hydraulic conductivity in fissured layer of hard-rock aquifers due to the geological structure of weathering profiles. Comptes Rendus Geosciences 335 (5), 451-460.

Massel, S.R., Furukawa, K., Brinkman, R.M., 1999. Surface wave propagation in mangrove forests. Fluid Dynamics Research 24, 219-249. 
Mazda, Y., Magi, M., Kogo, M., Hong, P.N.,1997. Mangroves as a coastal protection from waves in the Tong King Delta, Vietnam. Mangroves and Salt Marshes 1:127-135.

Météo-France, 2004. Indian ocean storm-surge study along Mayotte's shoreline. Unpublished Météo-France Réunion report (in French).

Miles, S.B., Keefer, D.K., 2009. Evaluation of CAMEL, comprehensive areal model of earthquake-induced landslides. Engineering Geology 104 (1-2), 1-15.

Monge, O, Chassagneux, D., Mouroux P., 1998. Methodology for liquefaction hazard studies: new tool and recent applications. Soil Dynamics and Earthquake Engineering 17 (7-8), 415425.

Mulvaney, T.J., 1851. On the use of self-registering rain and flood gauges in making observation of the relation of rainfall and floods discharges in a given catchment. Proceedings of the Institute of Civil Engineers of Ireland 4,18-31.

Nagarajan, R., Roy, A., Vinod Kumar, R., Mukherjee, A., Khire, M. V., 2000. Landslide hazard susceptibility mapping based on terrain and climatic factors for tropical monsoon regions. Bulletin of Engineering Geology and the Environment 58 (4), 275-287.

Nakamura, Y., 1989. A method for dynamic characteristics estimations of subsurface using microtremors on the ground surface. Quarterly Reports of Railway Technical Research Institute 30 (1), 25-33.

Obura, D., 2006. Impacts of the 26 December 2004 tsunami in Eastern Africa. Ocean \& Coastal Management 49 (11), 873-888. 
Pachauri, A.K., Pant, M., 1992. Landslide hazard mapping based on geological attributes. Engineering Geology 32 (1-2), 81-100.

Peng, W.F., Wang, C.L., Chen, S.T., Lee S.T., 2009. Incorporating the effects of topographic amplification and sliding areas in the modelling of earthquake-induced landslide hazards, using the cumulative displacement method. Computers \& Geosciences 35 (5), 946-966.

Perraudin, G., Benito, R., 2002. Cyclones that have passed-by or threatened Mayotte since 1858. Météo-France Mayotte report (in French).

Ramachandra, T. V., Subramanian, D. K., Joshi N.V., 1999. Hydroelectric resource assessment in Uttara Kannada District, Karnataka State, India. Journal of Cleaner Production 7 (3), 195-211.

Rey, J., Roullé, A., De Martin, F., Audru, J.C., Miehe, J.M., Bitri, A., Nédellec, J.L., 2006. Seismic hazard study and seismic movements, site of the professional college of Kaoueni (Mayotte). Open-file BRGM report no. RP-54470-FR (in French)

Roullé, A., Bernardie, S., Bitri, A., Miehe, J.M., Audru, J.C., Eucher, G. 2005. ) Seismic hazard study and seismic movements, site of Mamoudzou hospital (Mayotte). BRGM report no. Rapport BRGM/RC-53975-FR (in French).

Sabourault, P., Sedan, O., Audru, J.C., Mathon, C., Nédellec, J.L, Bitri, A., Bour, M., Lebrun B., 2002. Seismic microzonation of downtown Mamoudzou, Mayotte. BRGM report no RP51839-FR (in French). 
Saldivar-Sali, A., Einstein, H.H., 2007. A Landslide Risk Rating System for Baguio, Philippines. Engineering Geology 91 (2-4), 85-99.

Schmittner, K.E., Giresse, P. 1996. Modelling and application of the geomorphic and environmental controls on flash flood flow. Geomorphology 16 (4), 337-347

Seed, H.B., Idriss, I.M., Arango, I., 1983. Evaluation of Liquefaction Potential Using Field Performance . Journal of Geotechnical Engineering Division, ASCE, 1005 (3), 458-482.

Serrano-Pacheco, A., Murillo, J., García-Navarro, P., 2009. A finite volume method for the simulation of the waves generated by landslides. Journal of Hydrology 373 (3-4), 273-289.

Schindelé, F., Reymond, D., Hébert H., Heinrich, P., 2002. Geophysical hazards in the Marquesas Islands (French Polynesia), Géologie de la France 2, 39-52.

Soeters, R., van Westen, C.J., 1996. Slope instability recognition analysis and zonation. In: Turner, K.T., Schuster, R.L. (Eds.), Landslides: Investigation and Mitigation. Transportation Research Board National Research Council, Special Report, Washington DC, 129-177.

Stieltjes, L., 1988. Geological map of Mayotte at 1/50 000, BRGM (Ed.).

Stokoe, K.H., Nazarian, S., 1983. Effectiveness of ground improvement from spectral analysis of surface waves. Proceedings of the Eighth European Conference on Soil Mechanics and Foundation Engineering, Helsinki, Finland.

Tappin, D.R., Watts, P., McMurtry, G.M., Lafoy, Y.,Matsumoto, T., 2001. The Sissano, Papua New Guinea tsunami of July 1998; offshore evidence on the source mechanism. Marine Geology 175, 1-23. 
Terrier, M., Audru, J.C., Bour, M., Dominique P., 2000. Study of the regional seismic hazard of Mayotte island; determination of the reference earthquake. Open-file BRGM report no RP50250-FR (in French).

Thierry P., 1996. Mayotte island: inventory of natural hazards: mapping guidance at $1 / 50000$, Open-file BRGM report no 43292 (in French).

Thomassin, B.A., Arnoux, A., Coudray, J., Froget, C., Gout, B., Kouyoumontzakis, G., Masse, J.P., Reyre, Y., Reys, J.P., Vacelet E., 1989. The current sedimentation in Mayotte lagoon (island volcanic barrier reef, SW Indian Ocean) and its recent development in conjunction with terrigeneous input, Bulletin de la Société Géologique de France 8 (5), 12351251 (in French).

Van Westen, C.J., Rengers, N., Soeters, R., 2003. Use of geomorphological information in indirect landslide susceptibility assessment. Nature Hazard 30, 399-419.

Van Wyk de Vries, B., Kerle, N., Petley, D., 2000. Sector collapse forming at Casita volcano, Nicaragua. Geology 28 (2), 167-170.

Varnes, D.J., 1978. Slope movement types and processes In: Schuster R.L., Krizek R.J.,, Editors, Landslides, analysis and control. Transportation Research Board Special Report 176, National Academy of Sciences, Washington DC, 12-33.

Wilson, J.P., Gallant, J.C., 2000. Terrain analysis principles and applications. John Wiley and Sons, Inc., Toronto, Canada. 
Wong, T.S.W., Chen, C.N., 1994. Use of a tropical basin model to assess the importance of urbanized land condition on the increase of flood peak? Water Science and Technology 29(1-2), 155-161.

Wyns, R., Baltassat, J.M., Lachasagne, P., Legchenko, A.V., Vairon, J., Mathieu, F., 2004. Application of proton magnetic resonance soudings to groundwater reserve mapping in weathered basement rocks (Brittany, France)., Bulletin de la Société Géologique de France $175(1), 21-34$.

Yalcin, A., 2007. The effects of clay on landslides: a case study. Applied Clay Science 38 $77-85$.

Zinke, J., Reijmer, J.J.G., Thomassin, B.A., Dullo, W.C., Grootes, P.M. et Erlenkeuser, H., 2003. Postglacial flooding history of Mayotte Lagoon (Comoros Archipelago, southwest Indian Ocean). Marine Geology 194, 181-196. 